\title{
İleri evre halluks rijiduslu hastalarda yerli üretim total eklem artroplastisi ile tedavi sonuçlarımız
}

\author{
Our results with local production total arthroplasty in patients with advanced stage \\ hallux rijidus
}

Turan Cihan Dülgeroğlu, Nihat Demirhan Demirkıran, Mehmet Erduran

Özet

Amaç: Bu çalışmada ileri evre halluks rijiduslu hastalarda uyguladığımız 1. Metatarso-falangeal eklem total artroplastisi tedavi sonuçları değerlendirilmiştir.

Gereç ve Yöntem: Coughlin ve Shurnas sınıflamasına göre evre 3 ve 4 halluks rijidus tanılı 18 hastaya yerli üretim total başparmak artroplastisi uygulanmıştır. Ameliyat sonrası en az 12 ay takipli hastalarda retrospektif olarak eklem hareket açıklığı, görsel analog ağrı göstergesi (VAS) ve Amerikan Ortopedik Ayak ve Ayak Bileği Cemiyeti (AOFAS) skorları ile değerlendirme yapılmıştır.

Bulgular: Çalışmaya kabul edilen hastaların yaş ortalaması $(64,44 \pm 7,16)$ idi. Ortalama takip süresi $18,4 \pm 2,43$ aydı. 1. metatarso-falangeal eklem total artroplastisi yapılan hastalarda eklem hareket açıklığı $(p=0,001)$, VAS $(p<0,001)$ ve AOFAS $(p=0,001)$ skorlarında ameliyat öncesine göre anlamlı düzelme gözlendi. Takip süreleri boyunca implant yetmezliği, kırık oluşumu, enfeksiyon gibi komplikasyonlar gözlenmedi.

Sonuç: İleri evre halluks rijidus hastaları için güncel bir tedavi olarak total eklem artroplastisi eklem hareket açıklığında sağladığı artış ve ağrıyı azaltması sayesinde umut vadetmektedir.

Anahtar Kelimeler: Halluks rijidus, dejeneratif artrit, eklem artroplastisi.

Dülgeroğlu TC, Demirkıran ND, Erduran M. İleri evre halluks rijiduslu hastalarda yerli üretim total eklem artroplastisi ile tedavi sonuçlarımız. Pam Tıp Derg 2019;12:215-224.

\begin{abstract}
Purpose:The purpose of this study is to evaluate the pain and functional results of first metatarsophalangeal joint total arthroplasty treatment on patients with advanced stage of hallux rigidus.

Materials and Methods: Total joint arthroplasty was applied to 18 patients with stage 3 and 4 hallux rigidus according to Coughlin and Shurnas classification. Range of motion, visual analogue scale (VAS) and American Orthopedic Foot and Ankle Association (AOFAS) scores were evaluated twelve months after surgery.

Results: The average age of the patients was $64.44 \pm 7.16$. The mean follow-up period was $18.4 \pm 2.43$ months. Significant improvement was observed in the range of motion values $(p=0.001)$, VAS $(p<0.001)$ and AOFAS $(p=0.001)$ scores in patients with metatarsophalangeal joint total arthroplasty. Complications such as implant failure, fracture, or infection were not observed during the follow-up period.

Conclusion: Total joint arthroplasty is a promising treatment option for patients with advanced-stage hallux rigidus, providing satisfactory pain and functional results.
\end{abstract}

Key Words: Hallux rigidus, degenerative arthritis, arthroplasty.

Dülgeroğlu TC, Demirkıran ND, Erduran M. Our results with total joint arthroplasty in patients with advanced stage hallux rijidus. Pam Med J 2019;12:215-224.

Turan Cihan Dülgeroğlu, Dr. Öğr. Üyesi Department of Orthopedics, Dumlupinar University Evliya Celebi Education and Research Hospital, 43040 KÜTAHYA, e-posta: dr_turancihan@hotmail.com (orcid.org/0000-0002-9661-5418)

Nihat Demirhan Demirkıran, Uz. Dr. Department of Orthopedics, Dumlupinar University Evliya Celebi Education and Research Hospital, 43040 KÜTAHYA, e-posta: drdemirhandemirkiran@gmail.com (orcid.org/0000-0002-0724-9672) (Sorumlu yazar)

Mehmet Erduran, Doç. Dr. Department of Orthopedics, Dokuz Eylul University Hospital 35340, IZMiR, e-posta: dr.erduran@hotmail.com (orcid. org/0000-0002-0668-7224) 


\section{Giriş}

Halluks rijidus birinci metatarso-falangeal (1.MTF) eklemde görülen dejeneratif artrittir. Erişkin nüfusun yaklaşık \%10'unu etkileyen, 6 ve 7. dekadda pik yapan dejeneratif bir hastalıktır [1, 2]. Ağrı ve eklem hareket açıklığında (EHA) azalma tipik klinik bulgulardır. Çoğunlukla ailesel geçişli olmakla birlikte; kronik travma, kadın cinsiyet ve diğer bazı sebepler etiyolojide suçlanmaktadır [3]. Illeri evre halluks rijidusun cerrahi tedavisinde günümüzde hala fikir birliği bulunmamaktadır. Halluks rijidus tedavisinde eklem restorasyonu, artrodez veya rezeksiyon artroplasti seçenekleri ön plana çıkmaktadır ve hastaya uygun tedaviyi belirlerken yaş, aktivite yoğunluğu, artrozun derecesi, hastanın tedaviden beklentisi ve hastalığın evresi göz önüne alınmaktadır [4]. Coughlin ve Shurnas halluks rijidusu EHA, klinik ve radyolojik bulgularına göre sınıflamışlardır [5]. Halluks rijidus tedavisinde erken dönemde plantar gevşetme, çeylektomi, dekompresyon osteotomileri; daha ileri evrelerde ise rezeksiyon interpozisyon artroplastileri, hemiartroplasti, total eklem artroplastisi ve artrodez teknikleri tariflenmiştir [6-8]. Rezeksiyon interpozisyon artroplastisi sedanter, yaşlı, düşük fonksiyonel kapasiteli hastalara önerilir. İleri dönem halluks rijidusta düşük aktiviteli hasta gurubunda en başarılı tedavi artrodezdir. Ancak artrodezin dezavantajları; ayakkabı giymede zorluk, uzun iyileşme süresi, birinci sıra instabilitesi, parmakta kısalık ve transfer metatarsaljidir [7]. Artroplasti ile eklem fonksiyonlarının korunması, stabilite, parmak uzunluğunun korunması gibi avantajlar elde edilmektedir. Diğer taraftan artroplasti uygulamaları sonrası eklem sertliği, sinovit ve subluksasyon gibi komplikasyonlar da bildirilmiştir [8-10]. Bu çalışmada; konservatif tedaviden fayda görmeyen evre 3 ve 4 halluks rijidus tanılı hastalara uygulanan total artroplastinin erken dönem klinik sonuçları değerlendirilmiştir. Literatürde farklı materyallerle benzer çalışmalar bulunmaktadır ancak çalışmamız yerli üretim artroplasti sonuçlarını bildiren ilk çalışma olma özelliğini taşımaktadır.

\section{Gereç ve yöntem}

2015-2016 yılları arasında evre 3 ve 4 halluks rijidus nedeni ile total eklem artroplastisi uygulanan 26 hasta tarandı. Ameliyat öncesi grafilerinde halluks valgus vb dizilim bozukluğu, eklem patolojisi, çekiç parmak veya romatolojik hastalıklar gibi eşlik eden hastalıkları olan hastalar dişlanarak; en az 1 yıl takipli izole halluks rigidus tanılı 18 hasta geriye dönük olarak bu çalışmaya dahil edildi. Hastaların ağrı ve fonksiyonel skorları ile ameliyat öncesi ve sonrası grafileri değerlendirilmeye alındı. (Resim 1 ve 2)

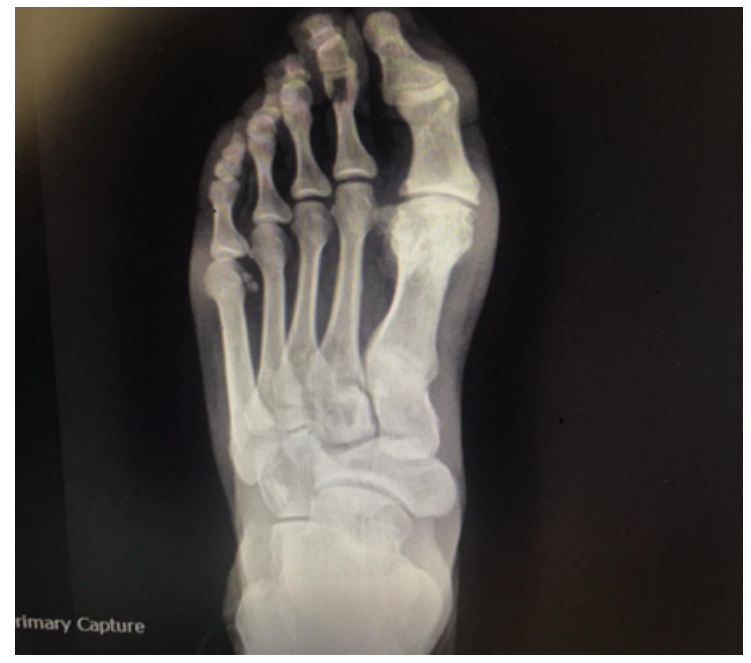

Resim 1a. 58 yaş bayan hastanın ameliyat öncesi grafileri.

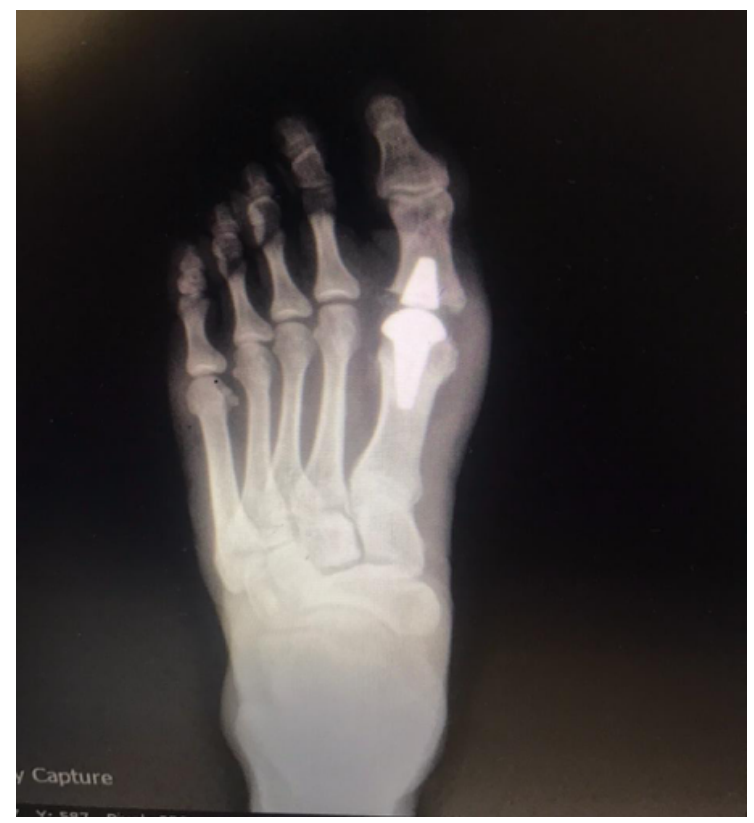

Resim 1b. 58 yaş bayan hastanın ameliyat sonrası grafileri. 


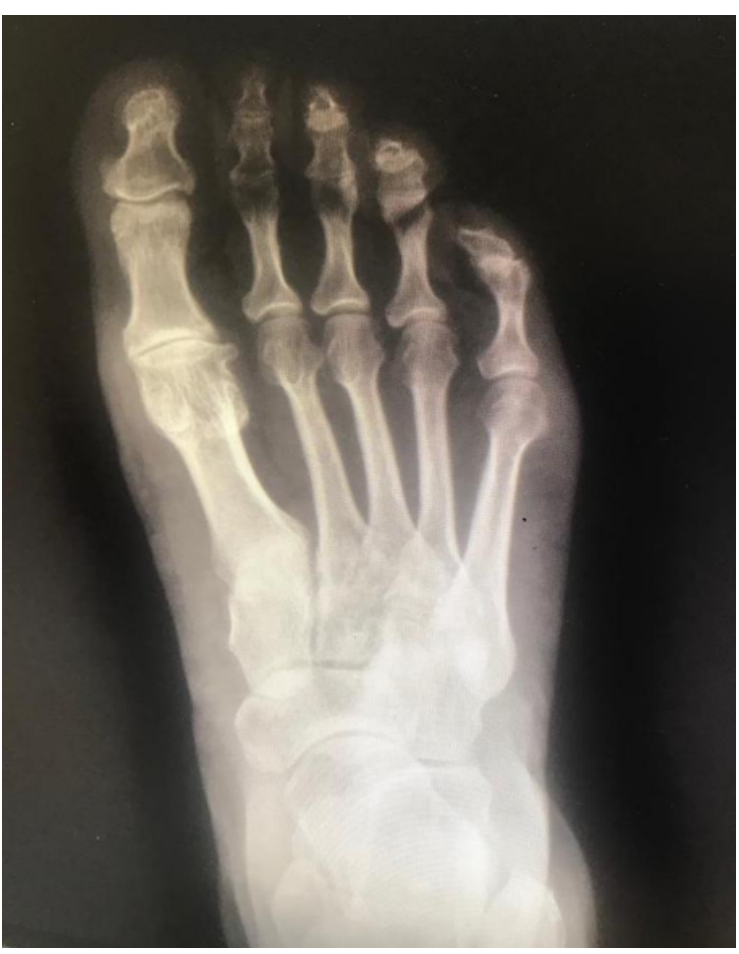

Resim 2a. 62 yaş bayan hastanın ameliyat öncesi grafileri.

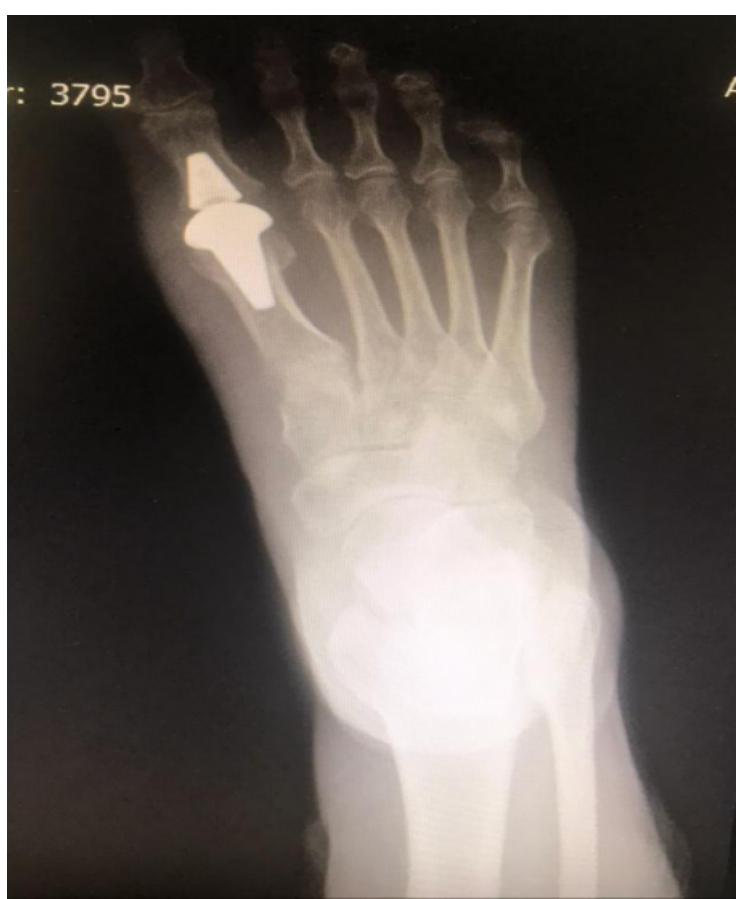

Resim 2b. 62 yaş bayan hastanın ameliyat sonrası grafileri.

Hastalara işlem öncesi cerrahi girişim hakkında detaylı bilgi verilerek ve bilgilendirilmiş onam belgeleri alınmıştı. Bu çalışma Helsinki Deklarasyonuna uygun şekilde gerçekleştirilmiştir. Yerli üretim olan EXEN (ALEDA Ankara/Türkiye) dört parçadan oluşan bir sistemdir. Falanks komponentine tespit edilen polietilen insert ve metatarsal komponente tespit edilen parlak kaplamalı parçadan oluşur (Resim 3)

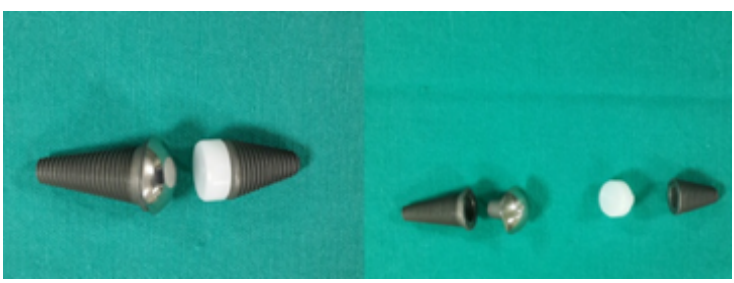

Resim 3. Yerli üretim EXEN/ ALEDA implantın komponentleri.

\section{Cerrahi uygulama}

Turnike kontrolü altında elastik bandajla ekstremitenin venöz kanı boşaltıldıktan sonra cerrahi saha povidon iyotla boyandı, ekstremite iobanlı drape ile örtüldü. Ekstensör hallusis longus tendonunun medialinden 1.metatarsophalangeal ekleme dorsal yaklaşımla cilt insizyonu yapıldı. Cilt altı dokular diseke edildi. Ekstensör tendon laterale doğru ekarte edildikten sonra kapsül açıldı ve 1.MTF eklem yüzüne ulaşıldı. Medial ve lateral kollateral ligamanlar korunarak implantasyonu sağlamak için 1.MTF eklemde mobilizasyon sağlandı. Eklem çevresindeki osteofitler temizlendi. Metatarsal ölçücü ile metatars başının uygun implant boyu ölçüldü. $2 \mathrm{~mm}$ drill metatars uzun aksına paralel olacak şekilde medulladan gönderildi. Drill ile hole açıldı dorsal kesi bloku yerleştirildi. Metatars başı dorsal kesisi yapılıp daha sonra proksimal falanks sizer kullanılarak proksimal falanks ölçüldü ve uygun implant tespit edildi. Deneme implantlar ile deneme yapıldıktan sonra implantlar yerleştirildi. 1.MTF eklem ROM aralığı kontrol edildi ve irigasyon sonrası katlar anatomik planda kapatıldı. Dren kullanılmadı. Elastik bandaj ile ekstremite sarıldı. Ameliyat sonrası ekstremite elevasyonu ve soğuk uygulama yapıldı. Pasif ROM egzersizlerine ameliyat sonrası 1. günde başlandı. Üç hafta boyunca kısmi yük verdirilen hastalara 6 hafta sonunda tam yük verdirildi. Hastalarda cerrahi sonrası erken dönemde enfeksiyon, yara problemi ve geç dönemde implant yetmezliği gibi komplikasyonlar gözlenmedi. Sütürlerin alınmasının ardından hastaların tolere edebildikleri kadar ayakkabı giymelerine ve günlük aktivitelerine dönmelerine müsaade edildi. 


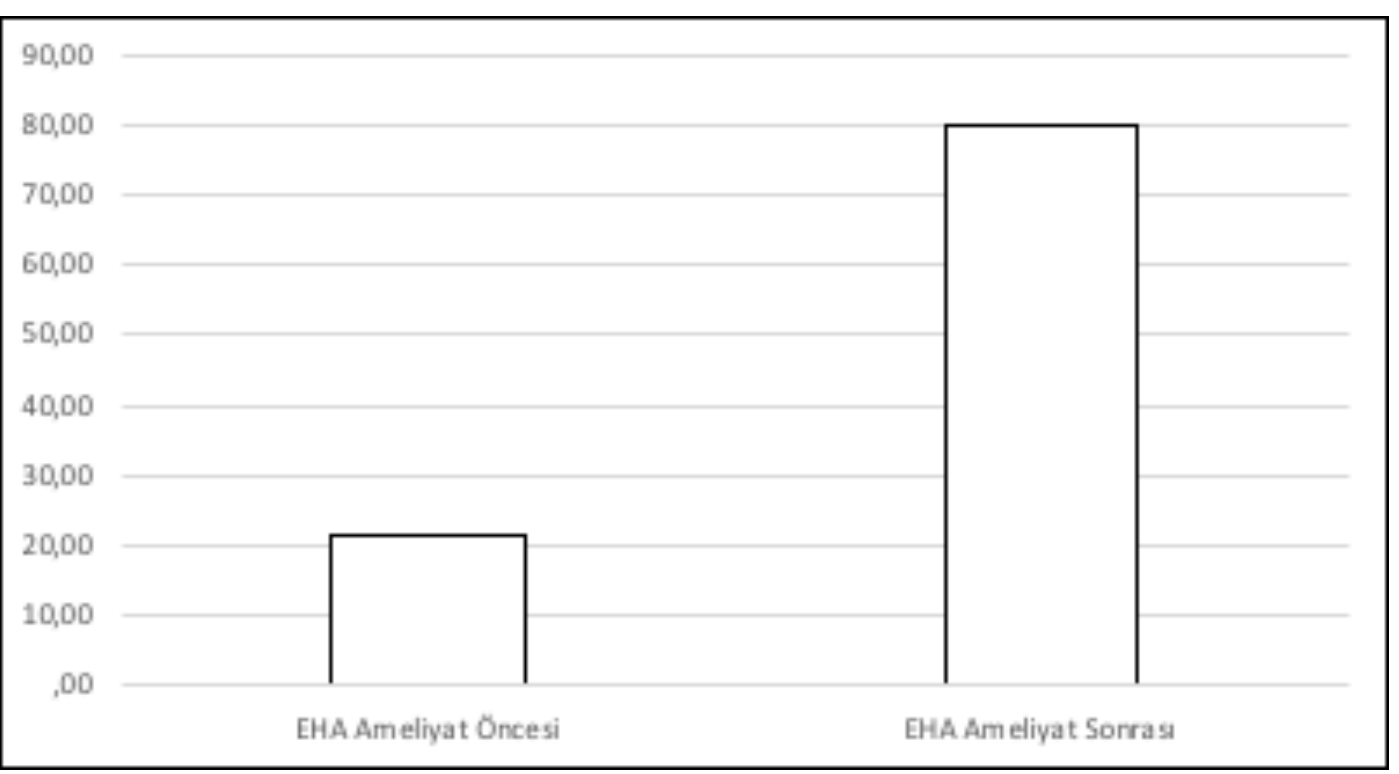

Grafik 1. Eklem Hareket Açıklığı değerlendirmesi.

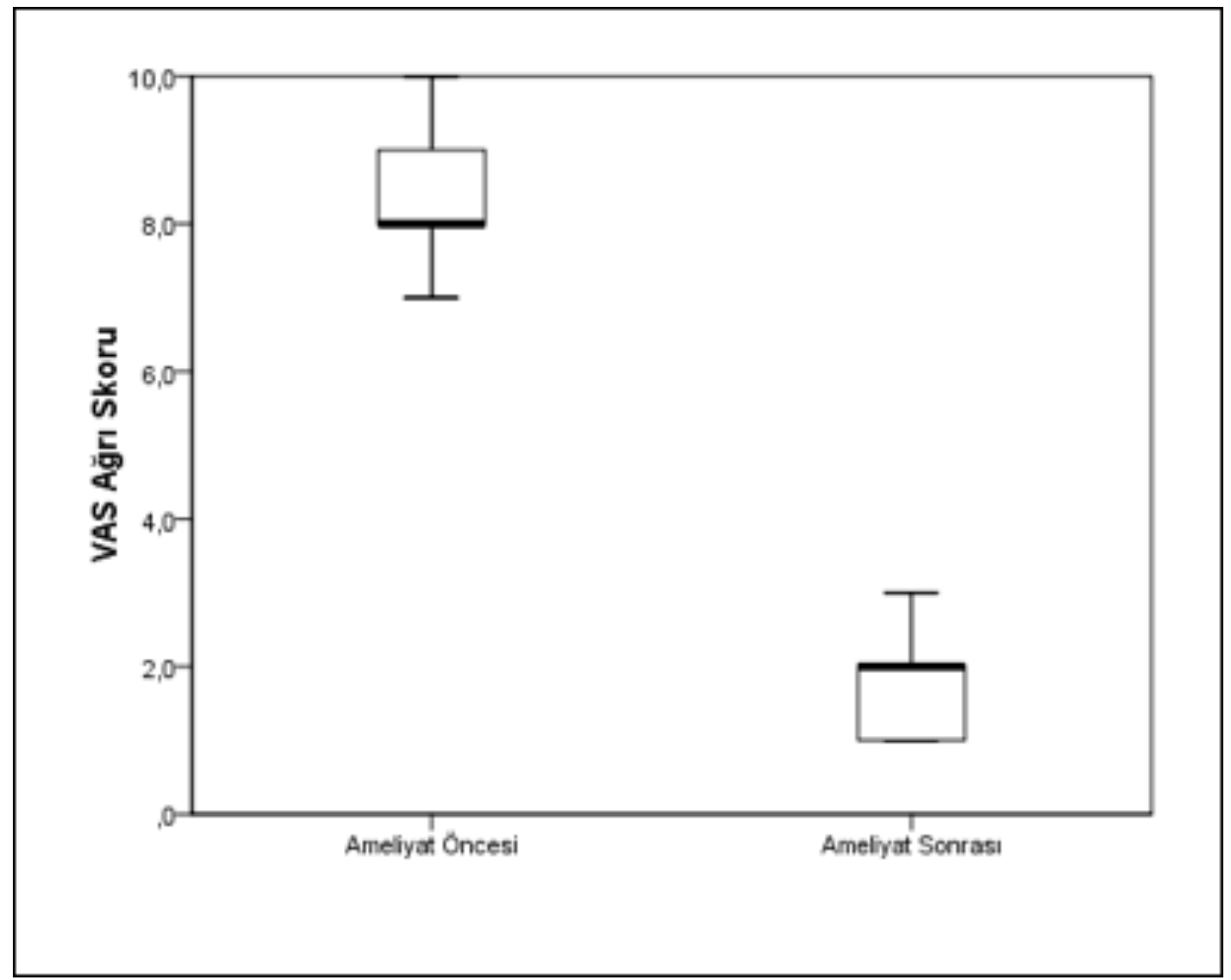

Grafik 2. VAS Skorları ameliyat öncesi ve sonrası karşılaştırması. 


\section{Değerlendirme}

AOFAS (The American Orthopedic Foot and Ankle Score) skorlama sisteminde 100 puan üzerinden ağrı (40 puan), (fonksiyon 50 puan) ve implant dizilimi (10 puan) (alignment) değerlendirilir. Çalışmada başka implantla kıyaslama yapılamayacağından dolayı implant dizilimi skorlaması yapılmamıştır ve 90 puan üzerinden değerlendirme yapılmıştır. Hasta dosyasından ameliyat öncesi eklem hareket açıklıkları ve ağrı değerlendirmesi ile AOFAS skorları elde edildi. Ameliyat sonrası en az 12. ayda AOFAS skorları aynı cerrah tarafından değerlendirildi. Ayrıca hastalardan ameliyat öncesi ve sonrası için ağrı değerlendirmesini görsel analog ağrı göstergesi (VAS) üzerinden yapıldı. EHA ölçümü gonyometri ile tek cerrah tarafından yapılmıştır.

\section{İstatistiksel Yöntem}

Değişkenlerin analizinde SPSS 22.0 (IBM, NY/ABD) programı kullanıldı. Verilerin normal dağılıma uygunluğu Shapiro-Wilk testi varyans homojenliği Levene testi ile değerlendirildi. Bağımsız iki grubun nicel verilere göre birbiri ile karşıllaştırılmasında Independent-Samples $T$ testi kullanıldı. Bağımlı nicel değişkenlerin iki tekrarlı ölçümlerinin birbiri ile karşılaştırılmasında parametrik testlerden Paired- Samples T testi Bootstrap sonuçlarıyla birlikte kullanılır iken parametrik olmayan testlerden Wilcoxon Signed Ranks Test ise Monte Carlo simülasyon sonuçları kullanılarak test edildi. Değişkenlerin birbiriyle olan korelasyonlarını incelemek için ise Pearson Correlation testi ve Spearman's rho testleri kullanılmıştır. Nicel değişkenler tablolarda ortalama \pm standart sapma, kategorik değişkenler ise $n(\%)$ olarak gösterildi. Değişkenler \%95 güven düzeyinde incelenmiş olup, 0,05 'ten küçük $p$ değeri anlamlı kabul edildi.

\section{Bulgular}

Olguların demografik verileri ve Coughlin ve Shurnas evrelemesine göre değerlendirmesi Tablo 1'de verilmiştir. Bu olguların 15'i $(\% 83,3)$ kadın, 3'ü $(\% 16,7)$ erkek hastaydı. Ortalama takip süresi 21,27 (en az 18-en çok 23) aydı. Yine olguların 11'inde sağ $(\% 61,1)$ ve 7 'sinde sol $(\% 38,9)$ ayakta halluks rijidus mevcuttu. 6 hasta $(\% 33,3)$ evre 3,12 hasta $(\% 66,7)$ evre 4 olarak sınıflandı. Hastaların yaş ortalaması 64,5 (en az 47-en çok 74) olarak saptandı. Eklem hareket açıklığı (EHA), VAS ağrı skoru ve AOFAS skorlarının değerlendirmesi Tablo 2'de verilmiştir. EHA'nın ameliyat öncesi ortalaması $(21,39 \pm 8,19)$ (15-45); ameliyat sonrası ortalamasından $(80,00 \pm 6,42)(65-90)$ daha düşük olup bu fark istatistiksel olarak anlamlı bulundu $(p=0,001)$. VAS ağrı skorunun ameliyat öncesi medyanı 8 (7-10) ameliyat sonrası medyan değerinden 2 (1-3) daha yüksek olup bu fark istatistiksel olarak anlamlıydı $(p<0,001)$. AOFAS skorlarının ameliyat öncesi ortalaması $(27,22 \pm 2,49)(24-32)$; ameliyat sonrası ortalamasından $(77,78 \pm 8,47)$ (65-88) istatistiksel olarak daha düşük bulundu $(p=0,001)$ (Tablo 2).

Yaş değişkeninin EHA, VAS ağrı skoru ve AOFAS değişkenlerinin ameliyat öncesi ve sonrası değerleri farkı ve takip süresi ile arasında anlamlı bir ilişki yoktu $(p>0,05)$ (Tablo 3$)$.

\section{Tartışma}

$\mathrm{Bu}$ çalışmada yerli üretim artroplasti implantlarıyla halluks rijidus tedavisinin eklem hareket açıklıkları, VAS, ve AOFAS skorları yönünden başarılı bir yöntem olduğu ortaya konmuştur. Çalışmamızdaki hastaların ilk ve son kontrolleri arasında ağrıda anlamlı derecede azalma ve fonksiyonel düzelme gözlenmiş ve en az bir yıllık takiplerinde komplikasyona rastlanmamıştır.

Halluks rijidus tedavisinde hastaların en büyük beklentisi ağrının azalması ve rahat mobilizasyondur [11]. Biz de çalışmamızda VAS skorlarında anlamlı bir azalma saptadık. Halluks rijidus da bir diğer cerrahi yöntem olan; eklem hareketini ortadan kaldırarak ağrısız bir metatarso-falangeal eklemin elde edildiği artrodez sonrasında da literatürde iyi sonuçlar bildirilmiştir [12-15]. Raikin ve ark. hemiartroplasti ile artrodezi karşılaştırdığı çalışmasında ağrı skoru ve memnuniyet açısından artrodezi üstün bulmuşlardır [12]. Artrodezi altın standart olarak tanımlayan bir diğer çalışmada ameliyat sonrası yü k verme ile $\% 91,1$ kaynama bildirilmiştir. Kumar ve ark. yaptıkları çalışmada artrodezli hastalarda \%100 başarıdan bahsetmişlerdir [15]. Ancak artrodezin; kaynamama, kaynama gecikmesi, metatarsalji, tarsometatarsal dejeneratif artrit, parmakta kısalık benzeri olumsuz sonuçları olabilmektedir. İlerlemiş halluks rijidusu olan ve günlük hayatta aktif hasta gurubu artrodez fikrine yeterince istekli görünmezler çünkü artrodez günlük aktiviteyi ve yürüyüşü kısıtladığından dolayı hasta için her zaman uyumlu değildir [16]. 
Tablo 1. Çalışmamızdaki hastaların demografik verileri ile işlem öncesi ve sonrası halluks rijidus evresi, ROM, VAS ve AOFAS değerleri.

\begin{tabular}{|c|c|c|c|c|c|c|c|c|c|}
\hline \multirow[t]{2}{*}{$\begin{array}{l}\text { Hasta } \\
\text { no }\end{array}$} & \multirow[t]{2}{*}{ cinsiyet } & \multirow[t]{2}{*}{ yaş } & \multirow[t]{2}{*}{ taraf } & \multirow[t]{2}{*}{ evre } & \multirow{2}{*}{$\begin{array}{l}\text { ROM } \\
\text { Önce } \\
\text { Sonra }\end{array}$} & \multirow{2}{*}{$\begin{array}{l}\text { VAS } \\
\text { Önce } \\
\text { Sonra }\end{array}$} & \multirow{2}{*}{$\begin{array}{l}\text { AOFAS Hallux- } \\
\text { First Ray Scale } \\
\text { Score } \\
\text { Önce } \\
\text { Sonra }\end{array}$} & \multirow[t]{2}{*}{ komplikasyon } & \multirow[t]{2}{*}{$\begin{array}{l}\text { Takip } \\
\text { (ay) }\end{array}$} \\
\hline & & & & & & & & & \\
\hline 1 & $\mathrm{~K}$ & 61 & $\mathrm{R}$ & 3 & $\begin{array}{l}20 \\
75\end{array}$ & $\begin{array}{l}9 \\
1\end{array}$ & $\begin{array}{l}27 \\
85\end{array}$ & Yok & 20 \\
\hline 2 & $\mathrm{~K}$ & 73 & L & 4 & $\begin{array}{l}25 \\
75\end{array}$ & $\begin{array}{l}8 \\
2\end{array}$ & $\begin{array}{l}24 \\
75\end{array}$ & Yok & 21 \\
\hline 3 & $\mathrm{~K}$ & 72 & $\mathrm{R}$ & 4 & 85 & $\begin{array}{l}10 \\
2\end{array}$ & $\begin{array}{l}24 \\
78\end{array}$ & Yok & 22 \\
\hline 4 & $E$ & 61 & L & 4 & $80^{15}$ & $\begin{array}{l}9 \\
1\end{array}$ & $\begin{array}{l}24 \\
88\end{array}$ & Yok & 19 \\
\hline 5 & $\mathrm{~K}$ & 58 & L & 3 & $\begin{array}{l}45 \\
90\end{array}$ & $\begin{array}{l}8 \\
2\end{array}$ & $\begin{array}{l}26 \\
85\end{array}$ & Yok & 20 \\
\hline 6 & $\mathrm{~K}$ & 62 & $\mathrm{R}$ & 3 & 20 & $\begin{array}{l}7 \\
1\end{array}$ & $\begin{array}{l}24 \\
88\end{array}$ & Yok & 19 \\
\hline 7 & $\mathrm{~K}$ & 47 & $\mathrm{R}$ & 4 & $\begin{array}{l}20 \\
85\end{array}$ & $\begin{array}{l}8 \\
3\end{array}$ & $\begin{array}{l}28 \\
65\end{array}$ & Yok & 23 \\
\hline 8 & K & 52 & L & 4 & $\begin{array}{l}25 \\
75\end{array}$ & $\begin{array}{l}9 \\
2\end{array}$ & $\begin{array}{l}30 \\
66\end{array}$ & Yok & 23 \\
\hline 9 & $\mathrm{~K}$ & 62 & L & 4 & $\begin{array}{l}20 \\
80\end{array}$ & $\begin{array}{l}8 \\
2\end{array}$ & $\begin{array}{l}32 \\
77\end{array}$ & Yok & 23 \\
\hline 10 & $\mathrm{~K}$ & 61 & $\mathrm{R}$ & 4 & $70^{15}$ & $\begin{array}{l}9 \\
1\end{array}$ & $\begin{array}{l}29 \\
88\end{array}$ & Yok & 23 \\
\hline 11 & K & 65 & $\mathrm{R}$ & 4 & $\begin{array}{l}25 \\
75\end{array}$ & $\begin{array}{l}8 \\
2\end{array}$ & $\begin{array}{l}30 \\
66\end{array}$ & Yok & 22 \\
\hline 12 & $\mathrm{~K}$ & 72 & L & 3 & $80^{20}$ & $\begin{array}{l}8 \\
1\end{array}$ & $\begin{array}{l}27 \\
69\end{array}$ & Yok & 22 \\
\hline 13 & $\mathrm{~K}$ & 72 & $\mathrm{R}$ & 3 & $\begin{array}{l}20 \\
85\end{array}$ & $\begin{array}{l}7 \\
1\end{array}$ & $\begin{array}{l}26 \\
75\end{array}$ & Yok & 22 \\
\hline 14 & $\mathrm{~K}$ & 73 & $\mathrm{R}$ & 4 & $\begin{array}{l}20 \\
85\end{array}$ & $\begin{array}{l}8 \\
2\end{array}$ & $\begin{array}{l}30 \\
66\end{array}$ & Yok & 21 \\
\hline 15 & $\mathrm{~K}$ & 74 & L & 4 & $65^{25}$ & $\begin{array}{l}9 \\
3\end{array}$ & $\begin{array}{l}28 \\
88\end{array}$ & Yok & 20 \\
\hline 16 & & 66 & $\mathrm{R}$ & 4 & 85 & $\begin{array}{l}9 \\
2\end{array}$ & $\begin{array}{l}27 \\
85\end{array}$ & Yok & 23 \\
\hline & $\mathrm{K}$ & & & & & & & & \\
\hline 17 & & 65 & $\mathrm{R}$ & 3 & 20 & $\begin{array}{l}7 \\
1\end{array}$ & $\begin{array}{l}27 \\
85\end{array}$ & Yok & 20 \\
\hline & $E$ & & & & & & & & \\
\hline 18 & & 65 & $\mathrm{R}$ & 4 & $80^{20}$ & $\begin{array}{l}8 \\
2\end{array}$ & $\begin{array}{l}28 \\
66\end{array}$ & Yok & 20 \\
\hline & $\mathrm{K}$ & & & & & & & & \\
\hline
\end{tabular}


Tablo 2. EHA, VAS ve AOFAS skorlarının ameliyat öncesi ve sonrasında değerlendirmesi.

\begin{tabular}{|c|c|c|c|c|}
\hline & $\begin{array}{c}\text { Ameliyat Öncesi } \\
\text { Ortalama } \$ S S .\end{array}$ & $\begin{array}{c}\text { Ameliyat Sonrası } \\
\text { Ortalama } \pm S S .\end{array}$ & $\begin{array}{c}\text { Fark (Ö-S) } \\
\text { Ortalama } \pm S S .\end{array}$ & $P$ Değeri \\
\hline EHA & $21,39 \pm 8,19$ & $80,00 \pm 6,42$ & $-58,61 \pm 9,82$ & 0,001 \\
\hline \multirow[t]{2}{*}{ AOFAS } & $27,22 \pm 2,49$ & $77,78 \pm 8,47$ & $-50,56 \pm 8,72$ & 0,001 \\
\hline & Median (Min./Max.) & Median (Min./Max.) & Median (Min./Max.) & \\
\hline VAS & $8(7 / 10)$ & $2(1 / 3)$ & $6(5 / 8)$ & $<0,001$ \\
\hline
\end{tabular}

Paired T Test (Bootstrap)-Wilcoxon Signed Ranks Test(monte Carlo)-SS.:Standart Sapma-Min.:Minimum-Max.:Maximum

Tablo 3. Yaşın; EHA, VAS ağrı skoru ve AOFAS ile ilişkisi.

\begin{tabular}{lcc}
\hline & $\mathbf{r}$ & $\boldsymbol{p}$ \\
\hline Yaş-EHA Fark(Ö-S) & $-0,147$ & 0,559 \\
Yaş-VAS Fark(Ö-S) & 0,377 & 0,123 \\
Yaş-AOFAS Fark(Ö-S) & $-0,331$ & 0,180 \\
Yaş-Takip Süresi Ay & 0,273 & 0,273 \\
EHA Fark(Ö-S)-VAS Fark(Ö-S) & $-0,457$ & 0,057 \\
EHA Fark(Ö-S)-AOFAS Fark(Ö-S) & $-0,146$ & 0,563 \\
EHA Fark(Ö-S)-Takip Süresi Ay & $-0,365$ & 0,136 \\
VAS Fark(Ö-S)-AOFAS Fark(Ö-S) & $-0,030$ & 0,905 \\
VAS Fark(Ö-S)-Takip Süresi Ay & 0,303 & 0,222 \\
AOFAS Fark(Ö-S)-Takip Süresi Ay & $-0,074$ & 0,770 \\
\hline
\end{tabular}

Spearman's rho Test, Pearson Correlation Test-r: Korelasyon Katsayısı

Çalışmamızda hem literatürdeki artrodez sonrası bildirilen düzeylerde ağrıda anlamlı bir azalma saptanmış; hem de total eklem artroplastisi ile metatarsofalangeal eklemin hareketi korunmuştur.

İlerlemiş halluks rijidusun tedavisinde bir diğer tedavi alternatifi keller rezeksiyon artroplastisidir. Bu yöntemle uzun dönem takip sonunda \%87 başarılı sonuç bildiren çalışmalar mevcuttur $[17,18]$. Transfer metatarsalji ve falankstaki aşırı kısalma bu cerrahide hasta memnuniyetini azaltan etmenlerdir [19]. Uyguladığımız artroplasti yöntemiyle ise falanks boyunda herhangi bir değişiklik olmamaktadır. Çalışmamızdaki 18 hastanın hiçbiri transfer metatarsalji şikayetleri tariflememiştir.

Artrodez yöntemlerinin tümünde ağrıyı ortadan kaldırmak için metatarsofalangeal eklemdeki hareket feda edilmektedir. Buna karşın çalışmamızda uygulanan eklem artroplastisi sonrası eklemin sabitlenmesinin aksine hareket açıklığının da anlamlı şekilde artııılabildiği izlendi. Metatarsofalangeal eklemin ağrısız ve stabil biçimde hareketine olanak sağlayabilecek ideal implantın arayışında günümüze kadar; silikon, kobalt krom, titanium implantlar denenmiştir [20]. Seramik implantların erken dönem iyi klinik sonuçları olsa da uzun dönem takipte yüksek revizyon cerrahisi bildirilmiştir [21-23]. Hemiartroplasti uzun süre kullanılmış bir yöntemdir ancak implant yetmezliği bu implantların yaygın bir sorunudur [24]. Metal veya silikon komponentli yüzey yenileme (resurfacing) artroplastileri ilk önce osteokondral defektlerin tedavisi için geliştirildi ve daha sonra ilerlemiş halluks rijidus tedavisinde kullanılmıştır. Her ne kadar total eklem artroplastisine oranla daha az 


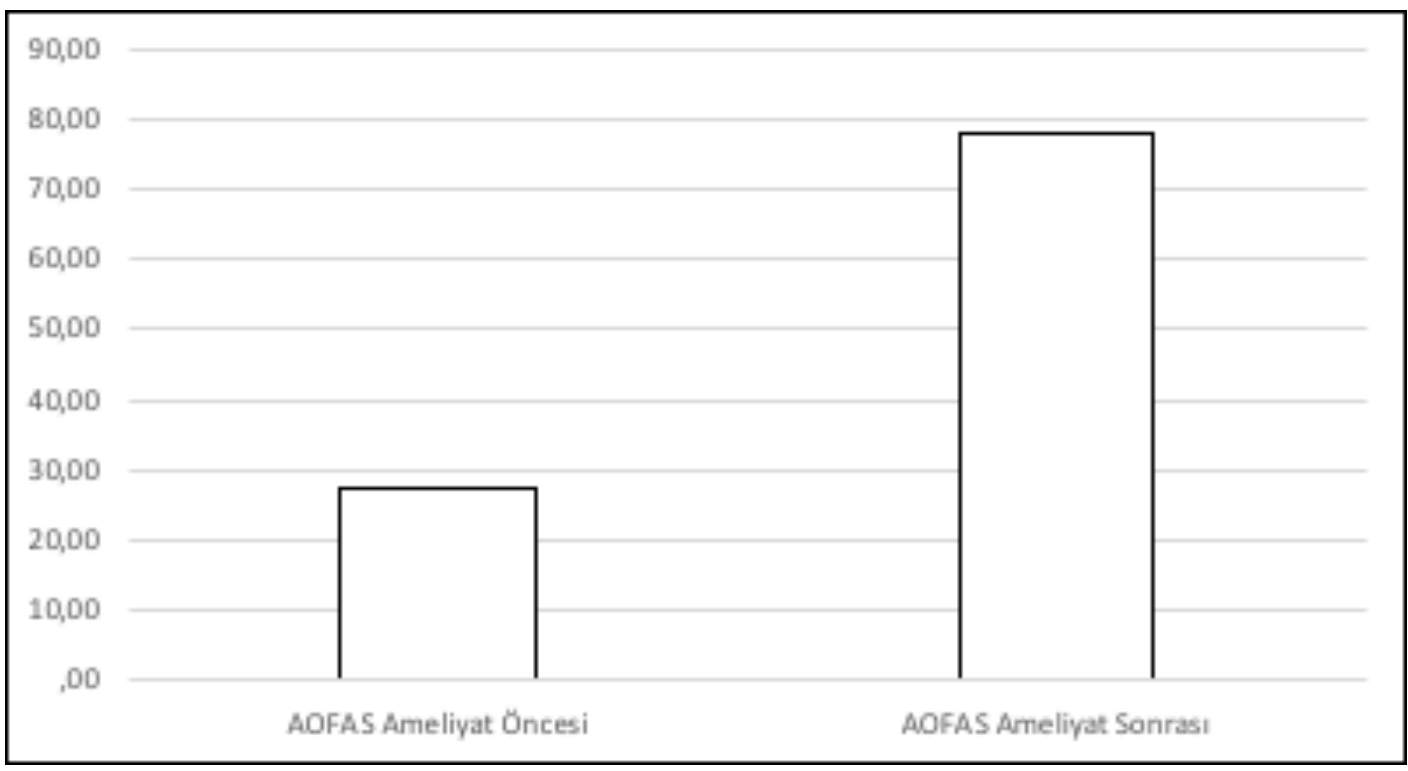

Grafik 3. AOFAS Skorları ameliyat öncesi ve sonrası karşılaştırması.

kemik defekti oluşturarak halluks rijidusu tedavi etse de uzun dönemde gevşeme, eklemde sertlik, osteoliz, silikon sinoviti, yumuşak doku reaksiyonu benzeri kötü sonuçlar yayınlanmıştır [25]. Çalışmamızda kullanılan titanyum alaşım ve polietilenden oluşan implantlar ile en az bir yıllık takip sonunda implant yetmezliği izlenmemiş ve hiçbir implant revizyon cerrahisine gitmemiştir.

Cook ve arkadaşlarının yayınladığı metaanalizde eklem artroplastisinin olumlu klinik sonuçlar verdiği bildirilmiştir [26]. Artroplastinin ilk kullanılmaya başladığı yıllarda yetmezlik (loosening) bildirilen birçok yayın literatürde mevcuttur. Seramik implantlar ile artroplasti sonuçlarının incelendiği bir çalışmada iyi klinik sonuçların yanında 18 aylık takip sonrası radyografik olarak belirgin gevşeme bulguları saptanmıştır [27]. Gibson ve ark. yaptıkları çalışmada artroplasti sonrası implant yetmezliklerinden dolayı artrodez sonuçlarını daha başarılı bulmuşlardır [28]. Bir diğer çalışmada total eklem artroplastisi, yüzey yenileme artroplastisi ve artrodez karşılaştırılmış. Her üç tedavide de VAS skoru belirgin azalmış olmasına karşın yalnızca total artroplasti ve yüzey yenileme artroplastisinde AOFAS skorlarında belirgin düzelme gözlemlenmiştir. Bu yönüyle ileri evre halluks rigidus tedavisinde artroplasti güvenilir bir tedavi olarak nitelenmiştir [29]. Biz bu çalışmada pressfit olarak uygulanan parlak kaplama yüzeyli total başparmak artroplastinin erken dönem klinik sonuçlarını sunduk. Çalışma sonunda bu implantla tedavinin eklem hareket açıklıkları,
VAS, AOFAS skorları ve hasta memnuniyeti açısından başarılı olduğunu gösterdik. Bu çalışmada AOFAS skorlama sistemine göre hastaların ilk ve son kontrollerinde ağrıda anlamlı derecede azalma ve fonksiyonel düzelme gözlenmiş ve komplikasyona rastlanmamıştır.

Bizim çalışmamızın kısıtlııklarından birincisi, karşılaştırmalı tedavi grubu olmamasıdır. Cerrahi alternatifler hastalara sunulduğunda; eklem hareketindeki kısıtlanma nedeniyle hastalar artrodeze isteksiz bulunmuşlardır. Diğer kısıtılık ise uzun dönem takip sonuçları olmamasıdır. Farklı implantların uygulandığı, prospektif geniş hasta serilerini içeren uzun dönem karşılaştırmalı çalışmalara intiyaç vardır.

Sonuç olarak yerli başparmak artroplastisi EXEN sistemi ile tedavi edilen ileri evre halluks rijidus hastalarının klinik sonuçlarında erken dönem anlamlı iyileşme olduğu görüldü. İleri evre halluks rijidus hastaları için total eklem artroplastisi tatmin edici ağrı ve fonksiyonel sonuçlar sağlayan bir tedavi seçeneğidir.

Çıkar İlişkisi: Yazarlar çıkar ilişkisi olmadığını beyan eder.

\section{Kaynaklar}

1. Ibrahim T, Beiri A, Azzabi M, Best AJ, Taylor GJ, Menon DK. Reliability and validity of the subjective component of the American Orthopedic Foot and Ankle Society clinical rating scales. J Foot Ankle Surg 2007;46:65-74. https://dx.doi.org/10.1053/j.jfas.2006.12.002 
2. Kitaoka HB, Alexander IJ, Adelaar RS, Nunley JA, Myerson MS, Sanders M. Clinical rating systems for the ankle-hindfoot, midfoot, hallux, and lesser toes. Foot Ankle Int 1994;15:349-353. https://dx.doi. org/10.1177/107110079401500701

3. Coughlin MJ, Shurnas PS. Hallux rigidus: demographics, etiology, and radiographic assessment. Foot Ankle Int 2003;24:731-743. https://dx.doi. org/10.1177/107110070302401002

4. Valentini R, De Fabrizio G, Piovan G. First metatarsophalangeal joint replacement with total arthroplasty in the surgical treatment of the hallux rigidus. Acta Biomed 2014;85:113-117.

5. Coughlin MJ, Shurnas PS. Hallux rigidus. Grading and long-term results of operative treatment. J Bone Joint Surg Am 2003;85:2072-2088.

6. Hasselman CT, Shields N. Resurfacing of the first metatarsal head in the treatment of hallux rigidus. Tech Foot Ankle Surg 2008;7:31-40. https://dx.doi. org/10.1097/BTF.0b013e318165c356

7. Kennedy JG, Chow FY, Dines J, Gardner M, Bohne $\mathrm{WH}$. Outcomes after interpositional arthroplasty for treatment of hallux rigidus. Clin Orthop Relat Res 2006;445:210-215. https://dx.doi.org/10.1097/01. blo.0000201166.82690.23

8. Fitzgerald JA, Wilkinson JM. Arthrodesis of the metatarsophalangeal joint of the great toe. Clin Orthop Relat Res 1981;157:70-77.

9. Yetkin $H$, Kanatı $U$, Songür $M$. Current treatment methods in hallux rigidus. TOTBID Dergisi 2006;6:95100.

10. Yee G, Lau J. Current concepts review: Hallux rigidus. Foot Ankle Int 2008;29:637-646. https://dx.doi. org/10.3113/FAI.2008.0637

11. Lundeberg T, Lund I, Dahlin L, et al. Reliability and responsiveness of three different pain assessments. $J$ Rehabil Med 2001;33:279-283.

12. Raikin SM, Ahmad J, Pour AE, Abidi N. Comparison of arthrodesis and metallic hemiarthroplasty of the hallux metatarsophalangeal joint. J Bone Joint Surg Am 2007;89:1979-1985. https://dx.doi.org/ 10.2106/ JBJS.F.01385

13. Berlet GC, Hyer CF, Glover JP. A retrospective review of immediate weightbearing afterfirstmetatarsophalangeal joint arthrodesis. Foot Ankle Spec 2008;1:24-28. https://dx.doi.org/10.1177/1938640007311920

14. Hyer CF, Glover JP, Berlet GC, Lee TH. Cost comparison of crossed screws versus dorsal plate construct for first metatarsophalangeal joint arthrodesis. J Foot Ankle Surg 2008;47:13-18. https://dx.doi.org/10.1053/j. jfas.2007.08.016

15. Kumar S, Pradhan R, Rosenfeld PF. First metatarsophalangeal arthrodesis using a dorsal plate and a compression screw. Foot Ankle Int 2010;31:797801. https://dx.doi.org/10.3113/FAI.2010.0797
16. Ter Keurs EW, Wassink S, Burger BJ, Hubach PC. First metatarsophalangeal joint replacement: Longterm results of a double stemmed flexible silicone prosthesis. Foot Ankle Surg 2011;17:224-227. https:// dx.doi.org/10.1016/j.fas.2010.08.001

17. Vallier GT, Peterson SA, LaGrone MO. The Keller resection arthroplasty: A 13- year experience. Foot Ankle Int 1991;11:187-194.

18. Hamilton WG, O'Malley MJ, Thompson FM, Kovatis PE. Capsular interposition arthroplasty for severe hallux rigidus. Foot Ankle Int 1997;18:68-70.

19. Akkurt $M O$, Şeşen $H$, Özdemir $M$, Çatma MF, Demirkale i. Reduced postoperative functional length ratio influences patient satisfaction in first metatarsophalangeal joint replacement. J Foot Ankle Surg 2016;55:743-747. https://dx.doi.org/10.1053/j. jfas.2016.02.007

20. Meriç G, Erduran M, Atik A, Köse Ö, Ulusal AE, Akseki D. Short-term clinical outcomes after first metatarsal head resurfacing hemiarthroplasty for late stage hallux rigidus. J Foot Ankle Surg 2015;54:173-178. https:// dx.doi.org/10.1053/j.jfas.2014.10.016

21. Duncan NS, Farrar NG, Rajan RA. Early results of first metatarsophalangeal joint replacement using the ToeFit-Plus ${ }^{\mathrm{TM}}$ prosthesis. J Foot Ankle Surg 2014;53:265-268.https://dx.doi.org/10.1053/j. jfas.2014.01.008

22. Redfern DJ, Coleridge SD, Bendall SP. Early failure of the Moje screw-fit ceramic metatarsophalangeal joint replacement. Foot 2003;13:204-208. https://dx.doi. org/10.1016/j.foot.2003.07.001

23. Nagy MT, Walker CR, Sirikonda SP. Second-generation ceramic first metatarsophalangeal joint replacement for hallux rigidus. Foot Ankle Int 2014;35:690-698. https:// dx.doi.org/10.1177/1071100714536539

24. Erdil M, Bilsel K, Imren $\mathrm{Y}$, et al. Metatarsal head resurfacing hemiarthroplasty in the treatment of advanced stage hallux rigidus: outcomes in the shortterm. Acta Orthop Traumatol Turc 2012;46:281-285.

25. Titchener AG, Duncan NS, Rajan RA. Outcome following first metatarsophalangeal joint replacement using TOEFIT-PLUS ${ }^{\text {TM }}$ : A mid-term alert. Foot Ankle Surg 2015;21:119-124. https://dx.doi.org/10.1016/j. fas.2014.10.005

26. Cook E, Cook J, Rosenblum B, Landsman A, Giurini J, Basile P. Meta-analysis of first metatarsophalangeal joint implant arthroplasty. J Foot Ankle Surg 2009;48:180190. https://dx.doi.org/10.1053/j.jfas.2008.10.009

27. Chee YH, Clement N, Ahmed I, Thomson CE, Gibson JN. Functional outcomes following ceramic total joint replacement for hallux rigidus. Foot Ankle Surg 2011;17:8-12. https://dx.doi.org/10.1016/j. fas.2009.11.005 
28. GibsonJN,ThomsonCE.Arthrodesisortotal replacement arthroplasty for hallux rigidus: a randomized controlled trial. Foot Ankle Int 2005;26:680-690. https://dx.doi. org/10.1177/107110070502600904

29. Erdil M, Elmadağ NM, Polat G, et al. Comparison of arthrodesis, resurfacing hemiarthroplasty, and total joint replacement in the treatment of advanced hallux rigidus. J Foot Ankle Surg 2013;52:588-593. https:// dx.doi.org/10.1053/j.jfas.2013.03.014 